\title{
Estimation of the density of the clay-organic complex in soil
}

\author{
Ewa A. Czyż $\dot{z}^{1 *}$ and Anthony R. Dexter ${ }^{2}$ \\ ${ }^{1}$ Department of Soil Science, Environmental Chemistry and Hydrology, University of Rzeszów, \\ Zelwerowicza 8b, 35-601 Rzeszów, Poland \\ ${ }^{2}$ Department of Soil Science, Erosion and Land Conservation, Institute of Soil Science and Plant Cultivation - State Research \\ Institute (IUNG-PIB), Czartoryskich 8, 24-100 Puławy, Poland
}

Received March 27, 2015; accepted July 23, 2015

A b s t r a c t. Soil bulk density was investigated as a function of soil contents of clay and organic matter in arable agricultural soils at a range of locations. The contents of clay and organic matter were used in an algorithmic procedure to calculate the amounts of clay-organic complex in the soils. Values of soil bulk density as a function of soil organic matter content were used to estimate the amount of pore space occupied by unit amount of complex. These estimations show that the effective density of the clay-organic matter complex is very low with a mean value of $0.17 \pm 0.04 \mathrm{~g}$ $\mathrm{ml}^{-1}$ in arable soils. This value is much smaller than the soil bulk density and smaller than any of the other components of the soil considered separately (with the exception of the gas content). This low value suggests that the clay-soil complex has an extremely porous and open structure. When the complex is considered as a separate phase in soil, it can account for the observed reduction of bulk density with increasing content of organic matter.

$\mathrm{K}$ e y w o r d s: complexed organic matter, density, soil clay content, soil organic matter content

\section{INTRODUCTION}

It is well-known that organic matter plays important roles in soil especially in relation to agriculture and the environment (Powlson et al., 2011). We noticed that the differences in the bulk densities of samples of the same soils having different contents of organic matter could not be accounted for only by the volume of the organic matter involved. We therefore decided to explore the hypothesis that the volume difference of the samples could be accounted for by the amount of clay-organic complex. This is the purpose of this paper.

\footnotetext{
*Corresponding author e-mail: ewac@univ.rzeszow.pl
}

Emerson et al. (1986) and Hassink and Whitmore (1997) explored the concept of a clay-organic matter complex in which the organic matter and the clay combine to form a new structure or phase. This structure does not necessarily have an integer stoichiometric ratio. In this concept, the clay can form a complex with available organic matter up to some maximum or saturation value, and any additional organic matter does not have enough clay available to complex it. Alternatively, the organic matter can become saturated with clay, and any additional clay does not have enough organic matter to complex it. The first of these situations is common in forest or pasture soils, whereas the second is typical in the soils in arable agriculture (Dexter et al., 2008). The saturation of soil clay with organic matter has been tested experimentally and shown to occur (Schjønning et al., 2012; Stewart et al., 2007).

Most of the organic matter in soil is in a decomposed state. When 'fresh' organic matter, such as crop residues and root exudates, are added to soil, the majority (90-95\%) becomes decomposed in the first year and most of the carbon is lost to the atmosphere as carbon dioxide. The part that remains (mostly molecular) becomes part of the soil organic matter $(O M)$ as described by Oades (1988).

We can easily see that most of the $O M$ is relatively old by considering one hectare of an imaginary agricultural field. We shall assume that plant production is $8 \mathrm{t} \mathrm{ha}^{-1}$. If $90 \%$ of this is lost rapidly (ie in the first year) then the annual input of organic matter to $O M$ is $0.8 \mathrm{t} \mathrm{ha}^{-1}$. We also consider the total amount of $O M$ in the top, or arable, layer. We shall assume that this layer is $0.25 \mathrm{~m}$ deep, has a dry bulk density of $1.6 \mathrm{t} \mathrm{m}^{-3}$, and has an organic matter content

(C) 2016 Institute of Agrophysics, Polish Academy of Sciences 
of $0.02 \mathrm{~kg} \mathrm{~kg}^{-1}$. This is equivalent to a content of $O M$ of $80 \mathrm{t} \mathrm{ha}^{-1}$. With this simple example, we can see that the $O M$ (that is stored in the soil) is of the order of 100 times greater than the net annual addition to the $O M$.

A consequence of this is that the great majority of the $O M$ is 'old' (ie several or many years). Different management practices lead to different 'equilibrium' organic matter contents. Long-term experiments at Rothamsted in England have shown that when management is changed, it can take at least 100 years for the new equilibrium content of organic matter to be attained although most of the change occurs in the first 20 years (Johnston and Poulton, 2005). However, the rate at which a new equilibrium is approached depends on the soil type, the nature of the additions of organic matter and on climatic factors. Because these changes are so slow, the annual input and output of $O M$ carbon are essentially equal.

It is necessary to consider the precise definitions of the quantities used. It is also necessary to be very careful to use consistent physical dimensions and units.

The soils are characterized conventionally by the size distributions of their mineral particles (p.s.d.) and by their contents of organic matter $(O M)$. These are all measured on a mass basis (ie gravimetrically). We note that the $O M(\%)$ is defined (ASTM D2974) as:

$$
O M=M_{O M}\left[100 /\left(M_{\min }+M_{O M}\right)\right],
$$

where: $M_{O M}$ and $M_{\min }$ are the masses of the organic matter and the soil mineral particles, respectively. We can see that $O M(\%)$ can in principle vary in the range $0-100 \%$. We assume that the content of $O M$ is proportional to the content of organic cabon $(O C)$, according to the average ratio of:

$$
O M=1.724 O C,
$$

as reported by Howard (1965).

The amounts of complexed and non-complexed organic carbon (COC and NCOC), and of complexed and noncomplexed clay (CC and NCC) may be calculated using the algorithmic method as described by Dexter et al. (2008) and as evaluated by Schjønning et al. (2012) using the following equations:

$$
\begin{aligned}
& C O C=O C \text { if } O C<(\text { clay } / \mathrm{n}), \text { else } C O C=(\text { clay } / \mathrm{n}), \\
& N C O C=(O C-C O C) \text { if }(O C-C O C)>0, \text { else } N C O C=0, \\
& C C=(n O C) \text { if }(\mathrm{n} O C<\text { clay }), \text { else } C C=\text { clay, } \\
& N C C=(\text { clay }-C C) \text { if }(\text { clay }-C C)>0, \text { else } C C=\text { clay. }
\end{aligned}
$$

A mean value of $\mathrm{n}$ was determined empirically by Dexter et al. (2008) to be $\mathrm{n}=10$, and we use this value to calculate Eqs (3-6). We can also see that in the special case when $O C=$ clay $/ \mathrm{n}$ (equivalent to $O M=1.724$ (clay/n)) then there will be no non-complexed $O M$ and also no noncomplexed clay because the complex will have used all of the components.
As mentioned above, all these quantities are measured on a mass basis. We continue using this basis because of interactions between the different components of the soil. For example, with a mixture of clay and sand, we cannot assume that the volume of the mixture is equal to the volume of the clay plus the volume of the sand when measured separately. This is because clay particles, being smaller, can fit in the interstices between the sand particles and may therefore contribute very little to the bulk volume of a mixture. So, the volumes are not conserved whereas the masses are. In this work, the only interaction that we allow is that of complexing between clay and organic matter as described in Eqs (3-6).

For the variation of bulk density with clay and organic matter content, we use the mean results for data previously discussed in Dexter et al. (2008). These come from subsets of the French SOLHYDRO data base (42 soils), from the French RMQS data base (614 soils) and from the Polish POLHYDRO data base (42 soils). These are discussed in Bruand et al. (2004), Jolivet et al. (2006) and Dexter et al. (2008), respectively. The general conclusion from these results is that regression of bulk density with clay and organic carbon as independent variables shows that neither of these variables yields coefficients that are statistically different from zero. However, when the amounts of complexed organic carbon $(C O C)$ are used, regressions that are statistically-significant are obtained. Here, we use the mean regression result:

$$
1 / D=0.59+0.076(C O C),
$$

or, in terms of complexed organic matter (COM) (after using Eq. (2)):

$$
1 / D=0.59+0.044(C O M) .
$$

We use the specific volume $(1 / D)$, so that the denominators of all of the terms have the same physical dimensions of mass $^{-1}$.

Because the density of the $C O C$ - clay complex cannot be determined exactly, we make use of its dominant effect, as shown in Eqs (7) and (8) to make some simplifying assumptions in our estimations.

\section{MATERIAL AND METHODS}

We shall consider in detail four different soils. Each of these had been tilled and cropped in the field for a number of years $(>20)$ with at least two different management regimes. Characteristics of the soils and some of their key properties are given in Table 1. For soils 1 and 2 the soils and treatments are described in Watts and Dexter (1997) and Dexter and Czyż (2000), respectively. For soil 3, the samples were collected from the top and the bottom of an eroded slope. For soil 4, the samples are as described by Gațe (2006). The soil samples were collected and stored at the water contents that they had in the field. The soils were not allowed to dry during storage. 
T a b l e 1. Details of the experimental soils with their locations and compositions

\begin{tabular}{|c|c|c|c|c|c|c|c|c|c|}
\hline \multirow{3}{*}{$\begin{array}{l}\text { Soil } \\
\text { number }\end{array}$} & \multirow{3}{*}{ Country } & \multirow{3}{*}{ Location } & \multirow{3}{*}{ Latitude } & \multirow{2}{*}{ Longitude } & Sand & Silt & Clay & & \multirow{3}{*}{$\begin{array}{l}\text { USDA soil } \\
\text { texture class }\end{array}$} \\
\hline & & & & & $>50 \mu \mathrm{m}$ & $2-50 \mu \mathrm{m}$ & $<2 \mu \mathrm{m}$ & $O M$ & \\
\hline & & & & \multicolumn{2}{|c|}{$\left({ }^{\circ}\right)$} & \multicolumn{2}{|c|}{$\left({\left.\mathrm{g} 100 \mathrm{~g}^{-1}\right)}\right.$} & & \\
\hline 1 & \multirow{3}{*}{ England } & Rothamsted & 51.804 & -0.362 & & & & & \\
\hline $1 \mathrm{~A}$ & & Highfield/fallow & & & 9 & 66 & 25 & 1.91 & silt loam \\
\hline 1B & & Highfield/rotation & & & 11 & 64 & 25 & 3.68 & silt loam \\
\hline 2 & \multirow{3}{*}{ Poland } & Grabów & & & & & & & \\
\hline $2 \mathrm{~A}$ & & rotation A & 51.350 & 21.664 & 71.5 & 26 & 2.5 & 1.05 & sandy loam \\
\hline $2 \mathrm{~B}$ & & rotation $\mathrm{B}$ & 51.349 & 21.665 & 73 & 24 & 3 & 1.43 & sandy loam \\
\hline \multirow[t]{2}{*}{3} & \multirow{4}{*}{ Poland } & Tomaszów & & & & & & & \\
\hline & & Lubelski & & & & & & & \\
\hline $3 \mathrm{~A}$ & & point A & 50.591 & 23.402 & 15 & 77 & 8 & 2.46 & silt loam \\
\hline 3B & & point B & 50.591 & 23.398 & 14 & 71 & 15 & 1.13 & silt loam \\
\hline 4 & \multirow{3}{*}{ Poland } & Żelisławki & & & & & & & \\
\hline $4 \mathrm{~A}$ & & treatment $\mathrm{A}$ & 54.167 & 18.659 & 61 & 29 & 10 & 2.30 & sandy loam \\
\hline $4 \mathrm{~B}$ & & treatment $\mathrm{B}$ & 54.166 & 18.659 & 75 & 18 & 7 & 1.21 & sandy loam \\
\hline
\end{tabular}

The use of two different histories such as management practices on the same soil for many years gives two different values of organic matter content together with the two corresponding values of soil bulk density. These two pairs of values enable the density of the clay-organic complex to be estimated for each soil.

We are interested in the density, $D_{\text {comp }}\left(\mathrm{g} \mathrm{ml}^{-1}\right)$ of the clay-organic complex. This may be defined as:

$$
D_{\text {comp }}=\frac{M_{\text {comp }}}{V_{c o m p}},
$$

where the numerator here is equal to the total mass of the complex which is equal to the mass of the complexed organic matter plus the mass of the clay with which it is complexed, or:

$$
M_{\text {comp }}=C O M+C C,
$$

in units of $\mathrm{g} 100 \mathrm{~g}^{-1}$ calculated using Eqs (2), (3) and (5).

The denominator in Eq. (9) is assumed to be equal to the change in the specific volume of the soil caused by the increment of complexed organic matter. If we consider two examples of the same soil that have two different contents of organic matter (perhaps a consequence of different cropping histories), then we may write (in units of $\mathrm{ml} \mathrm{g}^{-1}$ ):

$$
1 / D_{1}-1 / D_{2}=0.44\left(C O M_{1}-C O M_{2}\right) .
$$

In Eq. (11), the coefficient can either be the mean value presented in Eq. (8) or it can be determined from data for specific soils as presented in Tables 1-3. It is important to note here that we are considering only soils that are not saturated with organic carbon: that is, soils for which $O C$ $<$ clay/n from Eq. (3). This is almost always the case with arable agricultural soils. This is because tillage causes loss of soil organic matter which in turn leads to soil physical degradation such as reductions in the stability of soil in water (Watts and Dexter, 1997).

The mean value of the estimated value of the density of the organic matter-clay complex presented in this paper is based on the experimental data from four pairs of soils the descriptions of these, the measured values of the basic quantities and results derived from these are presented in Tables 1-3. Table 3 shows examples of how the density of the clay - organic matter complex was calculated from $\Delta M$ (which is the difference between the masses of clay organic matter complex in the two soils), divided by $\Delta V$ (which is the difference between the specific volumes of the two soil samples). The values obtained for the density of the clay - organic matter complex are presented in Table 3 and are found to be in the range $0.063-0.277 \mathrm{~g} \mathrm{ml}^{-1}$ with a mean value of $0.17 \pm 0.04 \mathrm{~g} \mathrm{ml}^{-1}$. 
T a b l e 2. Bulk densities and other quantities used in the calculations

\begin{tabular}{ccccccccc}
\hline $\begin{array}{c}\text { Soil } \\
\text { number }\end{array}$ & $\begin{array}{c}\text { Bulk density } \\
\left(\mathrm{g} \mathrm{ml}^{-1}\right)\end{array}$ & $O C$ & $C C$ & NCC & COC & NCOC & COM & NCOM \\
\cline { 3 - 8 } & 1.840 & 1.108 & 11.08 & 13.92 & 1.108 & 0 & 1.910 & 0 \\
\hline 1A & 1.570 & 2.135 & 21.35 & 3.65 & 2.135 & 0 & 3.681 & 0 \\
1B & 1.787 & 0.609 & 2.50 & 0 & 0.250 & 0.359 & 0.431 & 0.619 \\
2A & 1.694 & 0.829 & 3.00 & 0 & 0.300 & 0.529 & 0.517 & 0.912 \\
2B & 1.287 & 1.427 & 8.00 & 0 & 0.800 & 0.627 & 1.379 & 1.081 \\
3A & 1.530 & 0.655 & 6.55 & 8.45 & 0.655 & 0 & 1.129 & 0 \\
3B & 1.626 & 1.334 & 10.00 & 0 & 1.000 & 0.334 & 1.724 & 0.576 \\
4A & 1.348 & 0.702 & 7.00 & 0 & 0.700 & 0.002 & 1.207 & 0.003 \\
4B & & & & & 0 & & & \\
\hline
\end{tabular}

$C C$ and $N C C$ are complexed and non-complexed clay, $C O C$ and $N C O C$ are complexed and non-complexed organic carbon, and $C O M$ and $N C O M$ are complexed and non-complexed organic matter.

T a b l e 3. Specific volumes, masses and densities of complex

\begin{tabular}{|c|c|c|c|c|c|c|}
\hline \multirow{2}{*}{$\begin{array}{c}\text { Soil } \\
\text { number }\end{array}$} & $\begin{array}{c}\text { Bulk } \\
\text { density }\end{array}$ & $\begin{array}{c}\text { Specific } \\
\text { volume, } V\end{array}$ & $\Delta V$ & $\begin{array}{c}\text { Mass } \\
\text { complex }\end{array}$ & $\Delta M$ & $\begin{array}{c}\text { Density } \\
\text { of complex }\end{array}$ \\
\hline & $\left(\mathrm{g} \mathrm{ml}^{-1}\right)$ & \multicolumn{2}{|c|}{$\left(\mathrm{ml} 100 \mathrm{~g}^{-1}\right)$} & \multicolumn{2}{|c|}{$\left(\mathrm{g} 100 \mathrm{~g}^{-1}\right)$} & $\left(\mathrm{g} \mathrm{ml}^{-1}\right)$ \\
\hline $1 \mathrm{~A}$ & 1.840 & 54.35 & & 2.931 & & \\
\hline $1 \mathrm{~B}$ & 1.570 & 63.69 & 9.35 & 3.517 & 0.586 & 0.063 \\
\hline $2 \mathrm{~A}$ & 1.787 & 55.96 & & 2.931 & & \\
\hline $2 \mathrm{~B}$ & 1.694 & 59.03 & 3.07 & 3.517 & 0.586 & 0.191 \\
\hline $3 \mathrm{~A}$ & 1.287 & 77.70 & & 9.379 & & \\
\hline $3 \mathrm{~B}$ & 1.530 & 65.36 & 12.34 & 7.679 & 1.700 & 0.138 \\
\hline $4 \mathrm{~A}$ & 1.626 & 61.50 & & 11.724 & & \\
\hline \multirow[t]{3}{*}{$4 \mathrm{~B}$} & 1.348 & 74.18 & 12.68 & 8.207 & 3.517 & 0.277 \\
\hline & & & & & \multicolumn{2}{|c|}{ Mean $=0.17$} \\
\hline & & & & & \multicolumn{2}{|c|}{$\mathrm{SE}=( \pm 0.04)$} \\
\hline
\end{tabular}

\section{DISCUSSION}

Most of the world's organic carbon is located within the soil. There, it plays a huge role in stabilizing the soil and in making the soil suitable for agriculture. The soil organic carbon interacts with the soil clay surfaces (Manjaiah et al., 2010) and becomes sequestered and less available for microbial decomposition. If the organic carbon were not sequestered in the form of the clay-organic complex, then it could become oxidized and released to the atmosphere as carbon dioxide. The effects of atmospheric carbon dioxide on the global climate are well-known (Lal, 2014) and release of all of the soil organic carbon in this way would be catastrophic. Yet our knowledge and understanding of the clay-organic complex is limited. This paper seeks to increase our knowledge through determination of the density of the clay-organic complex.

The mean value obtained for the density of the clayorganic complex, and presented above, is much smaller than the bulk density of the soil or of any one of the components of soil, considered separately. This explains 
the disproportionately large effect of organic matter on soil structure and behavior (Dexter et al., 2008). These low values can be explained if the complex is very porous as a consequence of having an open structure, perhaps in the form of fibres or chains. Such porous structures are necessarily heterogeneous. Further research on the structure of clay - organic complexes is required to determine the structures involved.

The mean density of the complex may seem to be very small, but 'Aerogel', for example, has a much smaller density, typically $0.053 \mathrm{~g} \mathrm{ml}^{-1}$, although even smaller values are possible (http://www.aerogel.org for further information). We note that aerogel is an inorganic material.

The use of a larger data set would lead to a more accurate estimate of the mean value, and could be expected to lead to greater knowledge. Another factor that we expect to be important is whether the soil content of organic matter is increasing or decreasing with time. Increases are expected in cases where 'old' arable soils are converted to permanent pasture. In contrast, decreases are expected in cases where 'old' pasture soils are converted to continuous arable use (Johnston and Poulton, 2005). We conjecture that there may be some hysteresis in soil porosity as a function of content of organic matter because in the first case the increasing amount of soil complex will have to push other soil components apart whereas, in the second case, the soil will be able to collapse without resistance as the amount of complex decreases.

This could be an interesting topic for a future research project.

\section{CONCLUSIONS}

1. Measurements of the change in soil dry bulk density with content of organic matter may be used to estimate the density of the clay - organic matter complex.

2. An estimate of the mean effective density of the clay - organic matter complex was obtained as:

$$
D_{\text {comp }}=0.17 \pm 0.04 \mathrm{~g} \mathrm{ml}^{-1} \text {. }
$$

This estimated value for the average density of the clay - organic matter complex is much smaller than that of any of the other soil components (with the exception of the soil air).

3. The large observed effect of organic matter in reducing the bulk density of soil can be explained in terms of an effective mean low density of the clay - organic matter complex.

\section{REFERENCES}

ASTM D2974. Standard test methods for moisture, ash and organic matter of peat and other organic soils. Standard D2974-13. ASTM Int., West Conshohoken, PA, USA.

Bruand A., Duval O., and Cousin I., 2004. Estimation des propriétés de retention en eau des sols à partir de la bas de données SOLHYDRO. Étude Gest. Sols, 11(3), 323-332.

Dexter A.R. and Czyż E.A., 2000. Effects of soil management on the dispersibility of clay in a sandy soil. Int. Agrophysics, 14, 269-272.

Dexter A.R., Richard G., Arrouays D., Czyż E.A., Jolivet C., and Duval O., 2008. Complexed organic matter controls soil physical properties. Geoderma, 144, 620-627.

Emerson W.W., Foster R.C., and Oades J.M., 1986. Organomineral complexes in relation to soil aggregation and structure. In: Interactions of Soil Minerals with Natural Organics and Microbes. Soil Sci. Soc. Amer., Madison, WI, USA.

Gațe O.P., 2006. Estimation of the physical quality of some Polish arable soils. Ph.D. Thesis, Institute of Soil Science and Plant Cultivation (IUNG), Puławy, Poland.

Hassink J. and Whitmore A.P., 1997. A model of the physical protection of organic matter in soils. Soil Sci. Soc. Am. J., 61(1), 131-139.

Howard P.J.A., 1965. The carbon-organic matter factor in various soil types. Oikos, 15(2), 229-236.

Johnston A.E. and Poulton P.R., 2005. Soil organic matter: its importance in sustainable agricultural systems. Proc. Conf. Int. Fertiliser Society, December 14, Cambridge, UK.

Jolivet C., Boulonne N., and Ratié C., 2006. Manuel du réseau de mesures de la qualité des sols. Unité InfoSol, INRA, Orléans, France.

Lal R., 2014. Societal value of soil carbon. J. Soil Water Conservation, 69(6), 186A-192A.

Manjaiah K.M., Kumar S., Sachdev M.S., Sachdev P., and Datta S.C., 2010. Study of clay-organic complexes. Current Sci., 98(7), 915-921.

Oades J.M., 1988. The retention of organic matter in soils. Biogeochemistry, 5, 35-70.

Powlson D.S., Gregory P.J., Whalley W.R., Quinton J.N., Hopkins D.W., Whitmore A.P., Hirsch P.R., and Goulding K.W.T., 2011. Soil management in relation to sustainable agriculture and ecosystem services. Food Policy, 36 (Supplement 1), 72-87.

Schjønning P., de Jonge L.W., Munkholm L.J., Moldrup P., Christensen B.T., and Olesen J.E., 2012. Clay dispersibility and soil friability - testing the soil clay-to-carbon saturation concept. Vadose Zone J., 11 (1) doi: 10.2136/ vzj2011.0067

Stewart C.E., Paustian K., Conant R.T., Plante A.F., and Six J., 2007. Soil carbon saturation: concept, evidence and evaluation. Biogeochemistry, 86(1), 19-31.

Watts C.W. and Dexter A.R., 1997. The influence of organic matter in reducing the destabilization of soil by simulated tillage. Soil Till. Res., 42, 253-275. 